\title{
ASPECTOS PSICOSOCIALES, ECONÓMICOS Y CULTURALES QUE EXPLICAN EL FRIO INTERÉS CON QUE LOS PROFESIONALES ACOGEN LAS MATERIAS DE PREVENCIÓN DE RIESGOS PROFESIONALES
}

\author{
(PSYCHOSOCIAL, ECONOMIC AND CULTURAL ASPECTS THAT EXPLAIN WHY \\ PROFESSIONALS APPROACH MATTERS OF OCCUPATIONAL RISKS PREVENTION WITH \\ SUCH COLD INTEREST)
}

Luis María Romeo Sáez, Aparejador y Arquitecto Técnico Instituto Nacional de Seguridad e Higiene en el Trabajo ESPAÑA

RESUMEN

Análisis que nos coloca en el centro del huracán de la prevención y que nos lleva a ver que la seguridad debe estar en la "cabeza" de todos y que, por tanto, la "física" como la "química" sólo son remedios paliativos, pero no soluciones reales.
SUMMARY

An analysis that places us in the eye of the hurricane of Prevention and makes us realize that safety must be on everybody's mind and that therefore both "physics" and "chemistry" are only palliative measures and not real solutions.
Los debates sobre la prevención de riesgos profesionales continúa, sobre todo para aquellos que estamos interesados y/o vinculados a estas tareas; sin embargo, esto no ha hecho más que empezar.

Siempre he tenido la sensación de colaborar en una tarea marginal, "nadie" ha venido mostrando el mayor interés por estos aspectos, salvo los que han sufrido directa o responsablemente las consecuencias de algún siniestro. ¿Por qué esta frialdad, o aparente desidia, para atender las obligaciones que la ética profesional y la norma legal nos imponen? ¿En dónde reside la razón de su rechazo? ¿Es una materia tan marginal, que la mayoría de los técnicos prefiere ignorarla?

No sé a ciencia cierta cuáles podrán ser las razones que nos impulsan a actuar de este modo, pero de alguna for- ma pretendo explicar que hay factores objetivos y reales, de muy variada índole, que explican el estado de la frialdad actual.

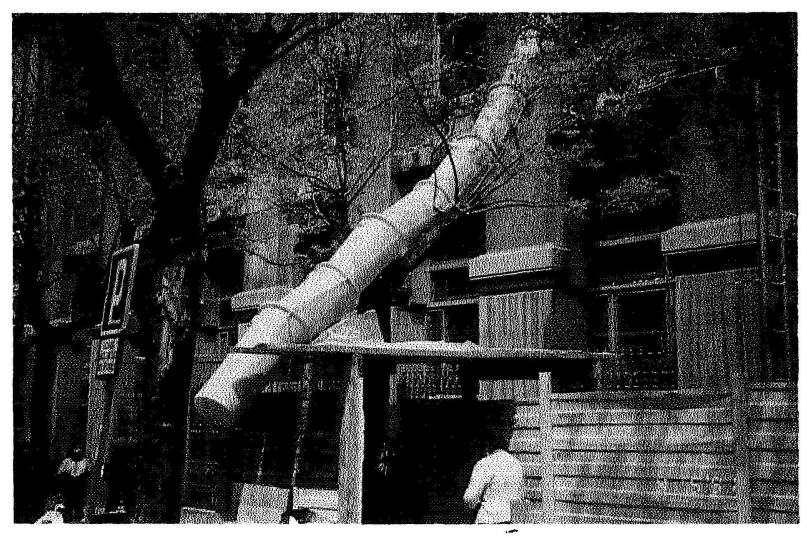

Caida de escombros a la batea. 


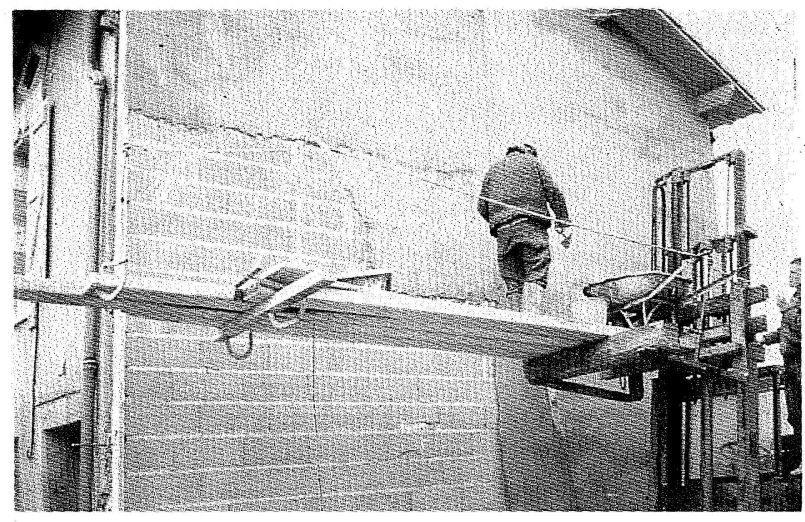

Andamios en equilibrio tecnológico.

Entre los posibles agentes causales destacamos los siguientes:

1. La Seguridad e Higiene en el Trabajo, es ésa "gran desconocida", de la que todos hablan y, es cierto, a la que todos acuden como recurso, pero la que nadie asume. Por ello no debemos buscar responsables de esta ignorancia colectiva, pero sí insistimos en que las aulas son, y debieron ser, el lugar idóneo para contactar primariamente con ella; labor ésta que no se hizo, a pesar de estar contemplada dentro de los programas universitarios.

2. La Seguridad "aparece y desaparece" con la propia obra, salvo en los elementos de mantenimiento diseñados a tal fin. Esto significa que la seguridad puede ser considerada como un "bien provisional", como una tarea que no mantiene su impronta. Nada de lo realizado por el técnico, que proyectó, ejecutó y controló ese "bien social" perdura. Con ello, se enajena al profesional de su "propiedad intelectual", aquella que le llevó a desarrollar el Estudio y/o Plan de Seguridad y plantearse su correspondiente seguimiento. En definitiva: "se le aliena de su capacidad creativa y tecnológica", por lo que pierde su interés convirtiéndose en materia obligadamente tediosa.

3. La Seguridad es considerada como "materia de interés normativo pero no técnica", cuyo principio y fin radica en el cumplimiento imperativo de la norma; craso error, ya que la realidad es bien distinta. Lo primero que se requiere para una correcta actuación en seguridad, es tener un conocimiento profundo del sistema constructivo, de las fases que necesariamente se irán sucediendo, de los medios que deberíamos emplear (maquinaria, materiales y herramientas, etc.); y la forma en que debieran ser instalados, aplicados o usados, para una correcta prevención de los riesgos que necesariamente se generan.

El segundo paso, y más delicado aún, viene al tratar de paliarse las demandas que la Ley impone en materia preventiva, con personal poco preparado o marginal, haciendo tareas que no sabe o que no le interesan para nada, cuando realmente lo que se pone en sus manos es el bien más preciado que la sociedad debe proteger, "la vida humana".

4. La Seguridad es estimada como un "gasto más" y, clario está, para hacer seguridad es menester invertir tanto en medios humanos como materiales, conllevando su costo correspondiente. Lo que no se dice es que esta inversión, dirigida en forma adecuada, resulta rentable.

Hoy es el día en que un número mínimo de profesionales se preocupa en indagar los fundamentos de esta cuestión (nuevo desacierto), dejándose llevar el colectivo por razonamientos decimonónicos, al pensar que aplicar el criterio del "no gasto" es ahorrar, sin darse cuenta tan siquiera que puede ser mucho más gravoso, para el resultado de la obra, el sufrir un solo accidente de cierta gravedad en el centro de trabajo, que hacer la inversión necesaria para esa obra en medios de prevención.

5. La Seguridad representa para los profesionales "una carga más", una carga añadida a las que actualmente soporta y sin posibilidades de trasladarla a otro destinatario o deshacerse de ella.

El Técnico se ve obligado a actuar en términos legales, ejerciendo el control cotidiano y minucioso, que la O.G.S.H.T. en su artículo décimo le exige. Como es de imaginar para poder cumplir con tales preceptos normativos se requiere "una actividad cuasi policial", que escapa en la mayoría de los casos por ir más allá de su propia entidad.

Si se emplea una secuencia constante de amonestaciones al personal por incumplimiento de sus obligaciones en materia de riesgos profesionales, el 
trabajador y/o sus representantes pueden entender como una persecución personal, cuando en la realidad se trata de atender estas obligaciones mencionadas que les son exigibles.

En definitiva, el cúmulo de dificultades añadidas de seguir comportamientos ajenos y que escapan a su control, son el origen en el técnico de una nueva frustación y por ende "un tributo social más a soportar".

6. La Seguridad se presenta ante el estadio técnico como "un problema estructural de la propia sociedad", donde el trabajador acude al mercado de trabajo sin la necesaria preparación para abordar por sí mismo este problema, y ni tan siquiera alcanza un grado mínimo de sensibilidad. Ello significa, que los pasos dados por la sociedad en su conjunto son escasos por no decir nulos, ya que un objetivo pri- mario a alcanzar debiera estar basado en lo que denominamos "la cultura de la seguridad".

De todo lo expuesto se puede concluir que, como cualquier verdad a medias, existen factores explicativos de la realidad del momento, aunque no sean justificativos de tal situación; al igual que no debe serlo para nuestra sociedad pensar que "el profesional por el hecho de serlo" necesariamente debe comportarse como un héroe. Más bien, debe ser el esfuerzo colectivo quien con unidad de objetivos actúe debidamente para corregir los déficits económicos, sociales y culturales que la sociedad actual tiene planteados.

Esos objetivos no deben tener otro fin que lograr el mejor beneficio que la sociedad pueda darse a sí misma: "la protección y mejora de la salud de cada uno de sus miembros".

\section{publicación del ICCET/CSIC}

\section{ALOJAMIENTO Y TECNOLOGÍA: ¿INDUSTRIALIZACIÓN ABIERTA? Julián Salas Serrano}

La experiencia nacional en construcción industrializada en la última década, aunque no abundante, puede resultar paralizante. Como reacción, este trabajo trata de elaborar y ordenar la información que, pegado al terreno, se ha acumulado durante los sesenta.

Auscultando tendencias avanzadas en otros paises y apoyándose en nuestra realidad cotidiana, el autor de este trabajo apuesta por la industrialización, presintiendo un futuro con pocos puntos en común con lo que en general, hasta bien reciente, se ha conocido como construcción industrializada.

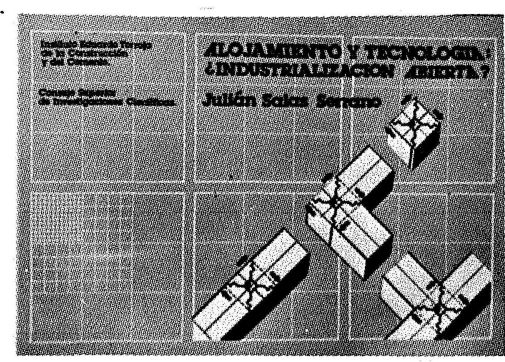

Se abre el trabajo con un prólogo del Profesor Ciribini en el cual, con rigor conceptual y desde su rica experiencia, analiza algunos de los conceptos más polémicos del fenómeno de industrialización del sector construcción. El autor recopila un conjunto de aportaciones de maestros de la arquitectura al lento proceso de evolución tecnológica y conceptual, continuando con un intento de respuesta realista a la interrogante que flota en el sector nacional: ¿réquiem por la industrialización?

Se dedican otros capitulos a revisar lo realizado y a encarar el futuro inmediato: el concepto de componente, su repercusión económica, la dificultad del proyecto a base de productos industriales, la nueva vigencia embrionaria de la construcción por medio de catálogos, los conceptos de flexibilidad e intercambiabilidad desde una óptica práctica... Especial atención dedica este trabajo a la exposición de lo que podíamos llamar nuevos derroteros de la coordinación dimensional, aportando una visión actualizada y pragmática de los enfoques más implantados en Europa.

Las siempre problemáticas interrelaciones entre normativa, calidad e industria se detallan de forma documentada y realista. Finaliza el trabajo con unas reflexiones dirigidas al ámbito empresarial y un esbozo de "reglas de juego" que faciliten al subsector la salida del uimpasse» actual.

Un volumen encuadernado en rústica, de $24 \times 16,5 \mathrm{~cm}$, compuesto de 160 páginas, con 109 figuras, 19 tablas y 86 referencias bibliográficas. 